\begin{abstract}
Iranica
Abstracta Iranica Revue bibliographique pour le domaine irano-aryen

Volume 34-35-36 | 2017

Comptes rendus des publications de 2011-2013
\end{abstract}

\title{
James Howard-Johnston. The Late Sasanian Army
}

\section{Rika Gyselen}

\section{(2) OpenEdition \\ Journals}

Édition électronique

URL : http://journals.openedition.org/abstractairanica/42329

DOI : 10.4000/abstractairanica.42329

ISSN : 1961-960X

Éditeur :

CNRS (UMR 7528 Mondes iraniens et indiens), Éditions de l'IFRI

\section{Référence électronique}

Rika Gyselen, « James Howard-Johnston. The Late Sasanian Army », Abstracta Iranica [En ligne], Volume 34-35-36 | 2017, document 47, mis en ligne le 30 juillet 2017, consulté le 26 septembre 2020. URL :

http://journals.openedition.org/abstractairanica/42329; DOI : https://doi.org/10.4000/

abstractairanica.42329

Ce document a été généré automatiquement le 26 septembre 2020.

Tous droits réservés 


\title{
James Howard-Johnston. The Late Sasanian Army
}

\author{
Rika Gyselen
}

\section{RÉFÉRENCE}

James Howard-Johnston. «The Late Sasanian Army », in: T. Bernheimer \& A. Silverstein, eds., Late Antiquity: Eastern Perspectives. Warminster, The Gibb Memorial Trust, 2012, p. 87-127.

1 Intéressante synthèse à partir des données permettant de concrétiser les connaissances sur l'armée sassanide à l'époque tardive. L'article comporte 7 chapitres et est assorti de 3 cartes comportant un minimum de toponymes favorisant ainsi la clarté des indications.

2 I. L'Iran sassanide et ses voisins. Un rappel sur les dangers pour la sécurité et la survie de la dynastie que constituent certaines régions à l'intérieur même de l'empire et aux frontières (fig. 1).

3 II. Principales composantes de l'empire sassanide. Description des régions qui constituent les bases de ressources et possèdent une population dense, et celles, montagneuses, qui sont censées protéger les zones fertiles et constituent aussi un réservoir de recrutement pour l'armée.

$4 \quad$ III. Défenses naturelles et défenses construites. L'A. passe en revue les principales bases militaires, les protections des frontières constituées par des murs et des forteresses, puis quelques grands travaux d'irrigation qui servent, du moins dans une certaine mesure, aussi à défendre des zones sensibles et importantes pour le pouvoir (fig. 2). On peut noter qu'il existait aussi des refuges souterrains pour la population de zones rurales exposées aux invasions.

5 IV. Chronologie des grands projets de constructions militaires. Réflexion de l'A. sur les initiatives sassanides en face des fortifications érigées par les Romains qui débutent vers les années 70/80 de notre ère et continuent au cours des premiers siècles 
sassanides. Dans le cas du Caucase où la défense contre des invasions nomades est tout aussi indispensable pour les Byzantins que pour les Sassanides, une collaboration consensuelle entre les deux puissances se met en place.

6 V. Nombre des troupes, recrutement, capacités. En l'absence de données contemporaines sassanides, cet aspect ne peut être traité qu'à partir de sources romaines ou de spéculations à partir de données archéologiques et historiques.

7 VI. Organisation de l'armée. H.-J. aborde ce sujet essentiellement à partir de sources arméniennes plus ou moins contemporaines. Bien sûr, certaines données ne sont pas en plein accord avec les sources primaires sassanides, d'ailleurs la carte (fig. 3) met en évidence l'hésitation de l'auteur pour inclure des régions comme l'Arménie, l'Ibérie, l'Albanie, le Balasagan et Siunja dans la circonscription militaire du kust-īĀdurbādagān, alors que les sources arméniennes le suggèrent.

8 VII. Objectifs stratégiques. L'A. met en avant que chacun des districts militaires dispose des moyens nécessaires, soit naturels soit grâce à l'infrastructure, pour protéger sa propre circonscription, et comment la cohésion entre les divers districts peut se mettre en place lorsqu'il s'agit d'organiser des campagnes militaires à l'extérieur de l'Iran sassanide.

9 La qualité de cette contribution peut faire oublier les quelques coquilles typographiques et petites imprécisions bibliographiques.

\section{AUTEURS}

\section{RIKA GYSELEN}

CNRS, Mondes iranien et indien 